weight babies. Doubts about the precision of the creamatocrit method must be tempered by the fact that it has an accuracy in the region of $10 \%(95 \%$ confidence limits). ${ }^{4}$ Protein loss was considerable but not related to technique or flow rate. The $\operatorname{IgA}$ loss has been spared, possibly due to differences in physico-chemical properties of milk proteins.

Two important clinical implications emerge. Firstly, these fat and protein losses will tend to invalidate any metabolic studies of the influence of feeding human milk on growth of low birthweight babies. It is possible that this is why Spencer was unable to show any correlation between energy intake and weight gain. ${ }^{4}$ Similarly, nutrient losses may be a potent cause for this lower weight gain showed by babies fed continuously by the nasojejunal route compared with those fed with intermittent boluses. ${ }^{5}$

Secondly, the extremely variable nutrient losses observed with continuous infusions must question the value of this method of feeding small infants particularly when there is no convincing evidence of its clinical benefit. If human milk is to be given this should be by bolus wherever possible.

The results of this study will most likely strengthen further the conviction of those who have recently questioned the value of human milk for preterm infants. We believe that it is premature as yet to discourage the use of human milk. Those who advocate more complicated formula feeding must show that it gives better short term results in terms of freedom from metabolic or iatrogenic disorder, and that long term growth and neurodevelopmental potentials are fulfilled. Those who believe in the desirability of human milk must pay attention to both the collection of milk and its delivery.

\footnotetext{
References

' Brooke OG, Barley J. Loss of energy during continuous infusions of breast milk. Arch Dis Child 1978;53:344-5.

${ }^{2}$ Spencer SA, Hull D. Fat content of expressed breast milk: a case for quality control. $\mathrm{Br}$ Med J 1981;282:99-100.

${ }^{3}$ Lucas A, Gibbs JAH, Lyster RLJ, Baum JD. Creamatocrit: a simple clinical technique for estimating fat concentration and energy value of human milk. $\mathrm{Br}$ Med $J$ 1978;i:1018-20.

${ }^{4}$ Spencer SA, Hendrickse W, Roberton D, Hull D. Energy intake and weight gain of very low birth weight babies fed raw expressed breast milk. $\mathrm{Br}$ Med $J$ 1982;285:924-6

5 Whitfield MF. Poor weight gain of the low birth weight infant fed naso-jejunally. Arch Dis Child 1982:57:597-601.

${ }^{6}$ Narayanan I, Singh B, Harvey D. Fat loss during feeding of human milk. Arch Dis Child 1984;59:475-7.
}

Correspondence to Dr R J Stocks, Department of Child Health, Leicester Royal Infirmary, Leicester LE2 7LX.

Received 31 August 1984

\title{
Vascular basis for malformations in a twin
}

\author{
T J DAVID \\ Department of Child Health, University of Manchester
}

SUMMARY A twin is described who was born with ileal atresia and hydranencephaly, the co-twin having died at about 24 weeks' gestation. If a macerated or autolysed twin is found at birth, the paediatrician should be alerted to the possibility of serious and not immediately obvious defects in the surviving infant.

The idea that malformations can only occur during embryogenesis in the first trimester is now out of date. Various cerebral defects clearly arise in the midtrimester. There is an association between the intrauterine death of a monozygotic twin and brain damage in the surviving twin. ${ }^{1}$ It has been suggested that death of the twin causes intrauterine disseminated intravascular coagulation, and that feto-fetal exchange of thromboplastic material from the dead fetus through vascular shunts in a monochorionic placenta causes cerebral infarction in the surviving twin. $^{2} 3$ Ileal atresia is thought to result from interference to the blood supply to a segment of the fetal bowel. ${ }^{4}$ This report describes a twin who was born with ileal atresia and hydranencephaly, the cotwin having died in the midtrimester of pregnancy.

\section{Case report}

This was the second pregnancy of a healthy 24 year old mother and 23 year old father. The first child was a healthy girl aged 2 years, there was no family history of malformations, and no consanguinity. No drugs were taken in pregnancy, which was normal until 24 weeks' gestation when twins were diagnosed by ultrasound scan. A scan at 26 weeks suggested that one of the twins had died, and this was confirmed on subsequent scans. Spontaneous onset 
of labour and normal delivery occurred at 38 weeks. The birthweight of the first twin was $2720 \mathrm{~g}$, and the Apgar score 9 at one minute. The second twin was severely macerated and autolysed. There was a single placenta. The cord to the first twin contained three vessels and was centrally inserted. The cord to the macerated twin was inserted marginally.

Intestinal obstruction on the first day of life in the surviving twin led to the discovery of ileal atresia which was treated surgically. Poor feeding, irritability, and grossly delayed development led to admission to hospital at 4 months of age. The occipitofrontal head circumference was $43.8 \mathrm{~cm}$, on the 97 th centile. The fundi were normal. Skull transillumination showed left hydranencephaly. Computed tomography showed that the left cerebral hemisphere had been replaced by fluid, with disorganised and abnormal development of the ventricular system on the right. The lymphocyte karyotype was normal and metabolic screening and a search for evidence of intrauterine infection were negative. At the age of 5 years he is severely handicapped and functioning at the level of a 6 week old child.

\section{Discussion}

The unusual feature of this child is the ability to be almost certain about the pathogenesis of his unique combination of hydranencephaly and ileal atresia. It is likely that death of a monozygotic co-twin caused release of thrombotic debris into the circulation of the surviving twin, leading to both the cerebral and intestinal defects.

Even excluding conjoined twins, there is an excess of congenital malformations in monozygotic twins compared with dizygotic twins or singletons. ${ }^{5}$ Either the monozygotic twinning and the malformation share a common aetiology, or the malformation is a consequence of the twinning process. Death of a twin causing embolisation and vascular disruption of a co-twin is thought to cause hydranencephaly, porencephaly, microcephaly, intestinal atresia, congenital skin defects, and limb amputation. ${ }^{5}$ Vascular disruption due to various reasons is increasingly being recognised as a cause of congenital malformations. ${ }^{6}$ If a macerated or autolysed twin is found at birth, the paediatrician should be alerted to the possibility of serious and not immediately obvious defects in the surviving co-twin.

This child was shown at a clinical meeting of the Section of Paediatrics, Royal Society of Medicine on 28 November 1980. I thank Dr D Donnai and Dr R W Newton for their help, and Miss Michelle Turner for typing the manuscript.

\section{References}

1 Yoshioka H, Kadomoto Y, Mino M, Morikawa Y, Kasubuchi Y, Kusunoki T. Multicystic encephalomalacia in liveborn twin with a still born macerated co-twin. J Pediatr 1979;95; 798-800.

2 Melnick M. Brain damage in survivor after in-utero death of monozygous co-twin. Lancet 1977;ii: 1287 .

3 Jung JH, Graham JM, Schultz N, Smith DW. Congenital hydranencephaly/porencephaly due to vascular disruption in monozygotic twins. Pediatrics 1984;73:467-9.

${ }^{4}$ Louw JH, Cywes S, Davies MRQ, Rode H. Congenital jejunoileal atresia: observations on its pathogenesis and treatment. $Z$ Kinderchir 1981;33:3-17.

5 Schinzel AAGL, Smith DW, Miller JR. Monozygotic twinning and structural defects. J Pediatr 1979;95:921-30.

6 Van Allen MI. Fetal vascular disruptions: mechanisms and some resulting birth defects. Pediatr Ann 1981;10:219-33.

Correspondence to Dr T J David, Booth Hall Children's Hospital, Manchester M9 2AA.

Received 20 August 1984

\section{Treatment of severe coagulation disturbances as a condition of improved prognosis in fulminant liver failure}

SUMMARY A favourable outcome of fulminant liver failure by replacement treatment with antithrombin III, prothrombin concentrate, fresh frozen plasma, and plasminogen is reported. Haemostatic balance was maintained and no severe bleeding complications occurred during the 15 days of disturbed liver function.
The mortality rate for patients with coma after hepatic necrosis is still between 65 and $90 \% .^{12}$ There is some evidence that the coagulation disturbances observed in the course of fulminant hepatic failure may act as an intermediary in the pathogenesis of the hepatic necrosis and that rapid correction of haemorrhagic diathesis may lead to an improved prognosis. ${ }^{34}$ We report our treatment of a child with acute hepatic coma of unknown origin. 